\title{
Pengaruh Dimensi Kompor Biomasa Terhadap Performansinya
}

\author{
Ahsonul Anam ${ }^{\text {a) }}$, Sugiono, Dwi Gunadi, dan Dahrudin \\ Balai Teknologi Bahan Bakar dan Rekayasa Disain (BTB2RD), BPPT \\ E-mail: ${ }^{\text {a) }}$ ahsonul.anam@bppt.go.id
}

Masuk:12 April 2017 Direvisi : 22 Mei $2017 \quad$ Disetujui : 17 Juni 2017

\begin{abstract}
Abstrak: Desain kompor berbahan bakar biomasa untuk keperluan memasak, dimaksudkan untuk mendapatkan performa yang optimal. Performa dilihat dari efisiensi pembakaran, efisiensi termal, dan emisi gas buang. Ketinggian ruang bakar kompor biomasa didesain sama dengan diameternya $(\mathrm{H}=\mathrm{D})$ atau 1-2 kali diameter $(\mathrm{H}=1-2 \mathrm{D})$. Pada penelitian ini digunakan dua buah kompor dengan perbedaan ketinggian ruang bakar $\left(\mathrm{H}_{1}=20 \mathrm{~cm}\right.$ dan $\left.\mathrm{H}_{2}=27 \mathrm{~cm}\right)$, dan diameter $(\mathrm{D}=20 \mathrm{~cm})$ dan menggunakan bahan bakar biomas yang sama. Performa dari kedua kompor diukur dari efisiensi termal, laju konsumsi bahan bakar, efisiensi pembakaran dan emisi gas buang. Pemantauan emisi gas buang dianalisa dengan menggunakan gas analyzer portabel. Hasil efisiensi pembakaran kedua kompor berbeda yaitu 99,5\% (kompor 1) dan 98,2\% (kompor 2). Efisiensi termal dari kompor 1 dan 2 adalah 25,4 dan 11,1\%. Laju konsumsi kompor 1 relatif stabil dibandingkan dengan kompor 2 selama pembakaran. Emisi CO yang dihasilkan dari kompor 1 dan 2 adalah 328 dan 555 ppm. Hasil gas buang SO dari kompor 1 dan 2 adalah 31 dan 38 ppm. Sedangkan emisi gas buang $\mathrm{NO}_{\mathbf{x}}$ dari tungku 1 dan 2 relatif berbeda dengan nilai 19 dan 13 ppm.
\end{abstract}

Kata kunci: kompor biomasa, efisiensi pembakaran, efisiensi termal, emisi gas buang

\begin{abstract}
Design of the stove based on biomass fuel for cooking system have been performed. The performances are evaluated by burning efficiency, thermal efficiency, and flow gas emission. Design of high $(H)$ and diameter $(D)$ of biomass furnace is 1 until 2 times of the diameter. In this research, the 2 stoves with difference of high of furnace $\left(H_{l}=20 \mathrm{~cm}\right.$ and $\left.\mathrm{H}_{2}=27 \mathrm{~cm}\right)$ and same of diameter $(D=20 \mathrm{~cm})$ and biomass fuel was used. The performance of stoves are measured from thermal, fuel consumption rate, burning efficiency and flow gas emission. Portable gas analyzer is used to monitor of emission gas (CO, $S O_{x}, N O_{x}$ ). The results of burning efficiency of both stoves are different, that is $99.5 \%$ (stove 1) and $98.2 \%$ (stove 2). Thermal efficiency of stove 1 and 2 are 25.4 and $11.1 \%$, respectively. The consumption rate of stove 1 is relatively stable depend on stove 2 as long as burning time. The CO emission of stove 1 and 2 are 328 and 555 ppm. The results of stove 1 and 2 for SOx emission are 31 and 38 ppm. The $N O_{x}$ emission of stove 1 and 2 are different with value of 19 and 13 ppm.
\end{abstract}

Keyword: biomass stove, burning efficiency, thermal efficiency, flow gas emission

\section{PENDAHULUAN}

Bahan bakar yang berasal dari fosil dalam waktu akhir-akhir ini sudah mulai dikurangi perannya karena sifatnya yang tidak dapat diperbarui. Selain itu, program konversi bahan bakar minyak ke gas belum bisa diterima sepenuhnya oleh masyarakat, terutama untuk kalangan menengah ke bawah. Di samping itu, terjadi 189 kali kasus ledakan tabung LPG 3 kg antara tahun 2008 hingga 2010 (Pusat Studi Kebijakan Publik, Puskepi), menambah keengganan masyarakat untuk menerima program pemerintah tersebut [1].

Meskipun banyak rumah tangga di Indonesia yang beralih ke kompor modern, namun sekitar 40 persen masih mengandalkan biomasa untuk memasak. Rumah tangga yang menggunakan kayu sedikit menurun dalam beberapa tahun terakhir, dari 49 persen pada tahun 2007 menjadi 40 persen pada tahun 2010 yaitu sekitar 24,5 juta rumah tangga di Indonesia masih mengandalkan kayu sebagai bahan bakar utama untuk memasak. Sekitar 11,7 juta rumah tangga tinggal di Jawa Timur, Jawa Tengah dan Jawa Barat. Kayu tetap menjadi bahan bakar memasak yang dominan di 18 dari 33 propinsi [2].

Biomasa merupakan sumber energi yang jumlahnya banyak tersedia di alam dan dapat diperbarui, sehingga berpotensi untuk dikembangkan menjadi sumber energi alternatif pengganti energi fosil [3]. Dari penggunaan 
awalnya yang berupa kayu, kemudian berkembang ke penggunaan biomasa yang telah diolah menjadi briket, tablet ataupun pelet. Kompor biomasa yang ada saat ini masih memiliki performansi yang kurang bagus, misalnya efisensi termal yang rendah serta emisi CO yang tinggi $[1,4]$. Disain kompor biomasa sangat berpengaruh terhadap performansinya. [5] Disain kompor niasanya disesuaikan dengan peruntukannya. Untuk keperluan rumah tangga, ketinggian $(\mathrm{H})$ ruang bakar kompor briket/biomasa biasanya didisain sama dengan diameternya $(\mathrm{H}=\mathrm{D})$ atau 1-2 kali diameter $(\mathrm{H}=1-2 \mathrm{D})[1,6,4]$.

\section{METODOLOGI}

Biomasa dari kayu yang dibuat dengan bentuk tertentu yang seragam (nilai kalor $4.500 \mathrm{kkal} / \mathrm{kg}$ ) digunakan sebagai bahan bakar. Pada penelitian ini, digunakan dua buah kompor dengan dimensi ruang bakar yang berbeda ketinggiannya, yaitu $20 \mathrm{~cm}$ (kompor 1) dan $27 \mathrm{~cm}$ (kompor 2), sedangkan dimeter ruang bakarnya sama yaitu 20 $\mathrm{cm}$. Bukaan udara untuk mengatur udara pembakaran yang masuk ke ruang bakar dibuka penuh (Gambar 1). Sedangkan pengisian bahan bakar biomasa dilakukan sekali isi (sistem batch) sesuai dengan kapasitas ruang bakar masing-masing kompor. Untuk kompor 1 adalah 1,5 kg sedangkan untuk kompor 2 adalah $2 \mathrm{~kg}$.

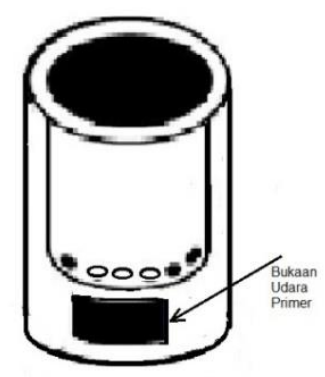

Gambar 1. Skema kompor dengan bukaan udara primer penuh.

Sebelum digunakan sebagai bahan bakar, biomasa diuji karakteristiknya yaitu uji proksimat, ultimat dan nilai kalor berdasarkan metode ASTM D5373 [7]. Evaluasi performansi ke dua kompor difokuskan pada tingkat efisiensi termal, efisiensi pembakaran, laju konsumsi bahan bakar dan emisi pembakarannya.

Untuk pengujian efisiensi termal, pengujian dilakukan dengan metode pendidihan air sebanyak 2 liter dalam panci sampai suhu air mencapai 100 derajat C. Pada saat suhu air sudah mencapai 100 derajat C, maka diganti dengan panci yang berisi air sebanyak 2 liter yang baru, sampai panci terakhir, yaitu suhu air tidak bisa mencapai 100 derajat C, pengujian dihentikan. Saat pengujian dilakukan pencatatan parameter performansi kompor antara lain suhu ambien, suhu awal air dalam panci, suhu akhir air dalam panci, suhu api tepat di bagian atas kompor, suhu dinding kompor bagian atas dan bawah. Pengujian efisiensi termal dilakukan dengan menempatkan 6 titik pengukuran yaitu 2 titik pada lidah api, 1 titik pada dinding kompor bagian atas, 1 titik pada dinding kompor bagian bawah, 1 titik udara ambien dan 1 titik air dalam panci (Gambar 2). Sistem pengukuran suhu menggunakan data logger dengan sisitem menyimpanan data pada waktu cuplik 1 menitan. Panas yang digunakan untuk mendidihkan air dibandingkan dengan kandungan kalori dalam bahan bakar digunakan sebagai dasar perhitungan efisiensi termal, seperti terlihat pada rumus 1 .

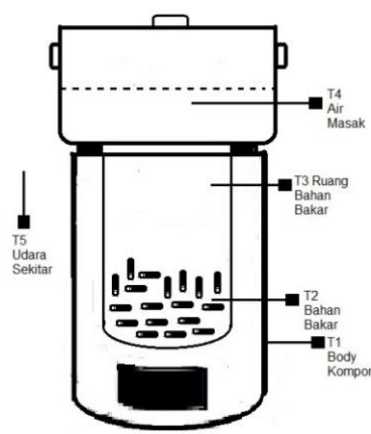

Gambar 2. Skema pengujian efisiensi termal. 
Efisiensi termal dihitung menggunakan rumus (1) di bawah ini :

$$
\eta_{T}=\frac{m_{w} \cdot C_{p_{w}} \Delta T_{w}}{H H V_{f u e l}}
$$

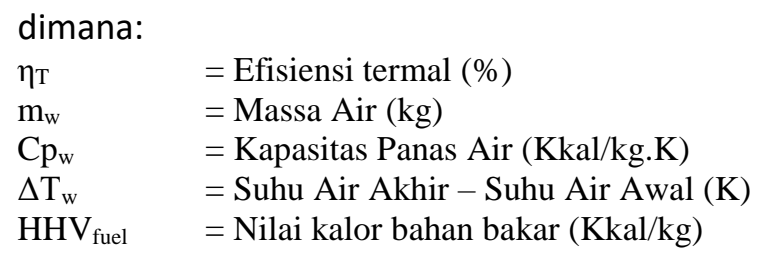

Untuk pengujian efisiensi pembakaran, laju konsumsi dan uji emisi (Gambar 3), pelaksanaan pengujian dilakukan secara bersamaan dalam suatu ruangan yang didisain khusus sebagai simulasi dapur yang dilengkapi dengan cerobong untuk pengukuran emisi gas buang $\mathrm{CO}, \mathrm{SO}_{\mathrm{x}}$, dan $\mathrm{NO}_{\mathrm{x}}$ menggunakan gas analyzer [8]. Pengukuran dilakukan dengan menempatkan kompor uji di atas timbangan sehingga pengurangan bahan bakar dapat dipantau dan direkam dengan interval waktu tertentu (2 menit), dimulai saat bahan bakar mulai terbakar sampai dengan nyala api dalam ruang bakar padam. Bersamaan itu pula pada akhir pengujan, dilakukan uji kandungan karbon dalam abu sisa pembakaran (unburn carbon) menggunakan metode ASTM D5373 ${ }^{1)}$, yang digunakan untuk menghitung efisiensi pembakaran menggunakan rumus 2.

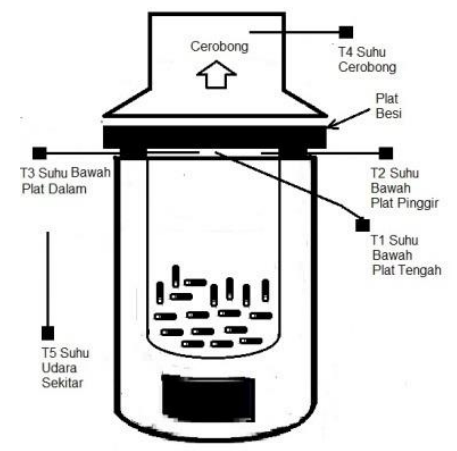

Gambar 3. Skema pengujian efisiensi pembakaran, laju konsumsi bahan bakar dan emisi.

Efisiensi Pembakaran dihitung berdasarkan konversi atom karbon yang ada dalam bahan bakar dan dalam abu sisa pembakaran menggunakan rumus (2) di bawah ini :

$$
\eta_{\text {comb }}=\frac{C_{\text {fuel }}-C_{a s h}}{C_{f u e l}}
$$

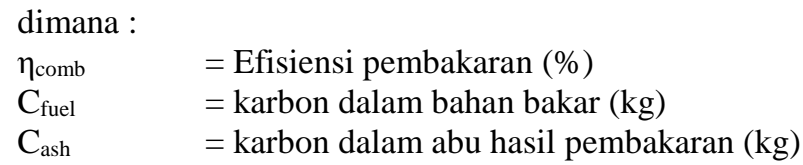

\section{HASIL DAN PEMBAHASAN}

Hasil pengujian efisiensi termal kedua kompor ditampilkan dalam bentuk grafik profil suhu pada Gambar 4. Profil suhu yang ditampilkan hanya pada 3 titik pengukuran utama yaitu 2 titik pengukuran lidah api dan 1 titik di air dalam panci. 


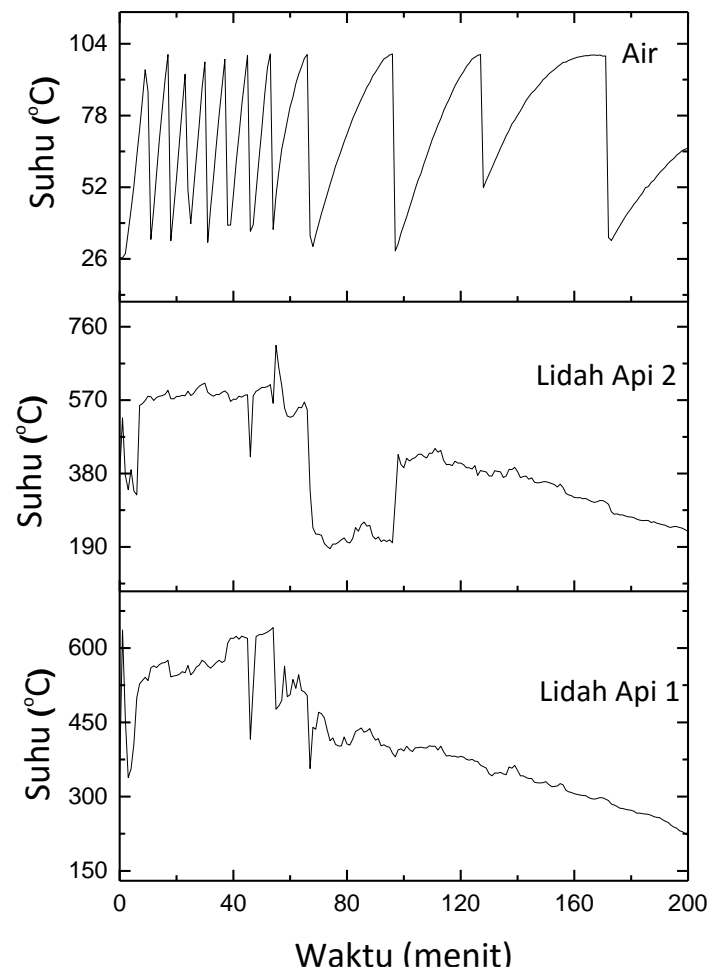

(a)

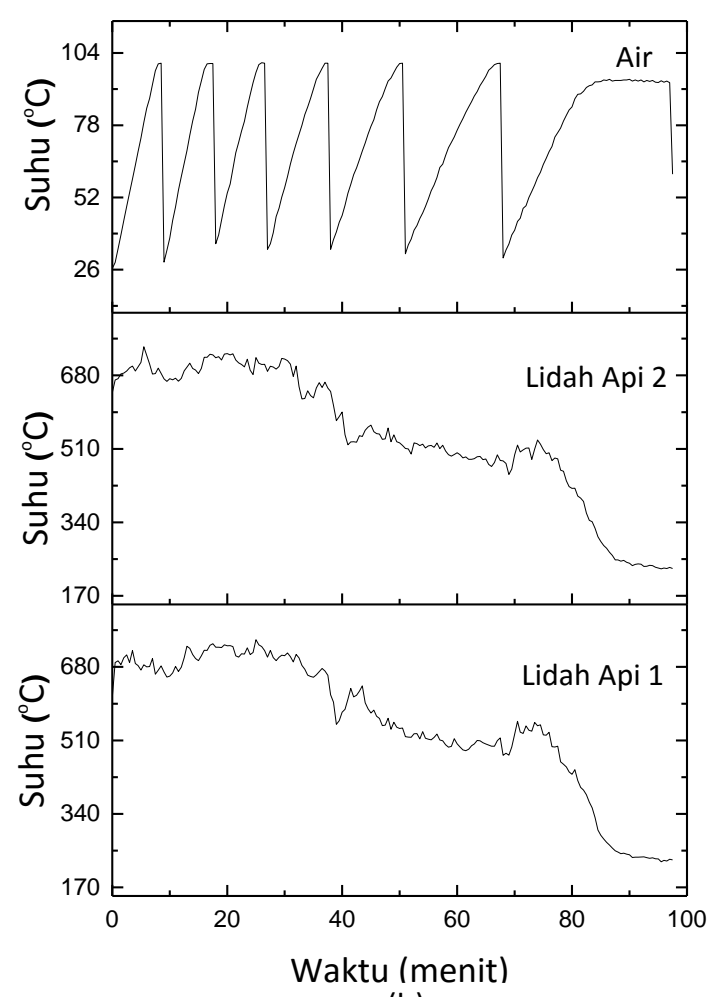

(b)

Gambar 4. Hasil Uji a) Kompor 1 dan b) Kompor 2.

Dari Gambar 4, khususnya grafik profil suhu air dalam panci, puncak grafik adalah siklus suhu air mencapai $100{ }^{\circ} \mathrm{C}$ dan 1 siklus pendidihan air dimulai dari suhu ambien sampai dengan suhu air mencapai $100{ }^{\circ} \mathrm{C}$. Pada kompor 1 (Gambar 4a), mampu mendidihkan air 2 liter sebanyak 11 kali, sedangkan kompor 2 (Gambar 4b) hanya mampu mendidihkan air 2 liter sebanyak 7 kali. Efisiensi termal kompor 1 adalah 25,4\% sedangkan kompor 2 sebesar $11,1 \%$.

Suhu di lidah api pada kompor 1 mencapai $600^{\circ} \mathrm{C}$ dan berlangsung sekitar 66 menit pertama dan berhasil mendidihkan air sebanyak 8 kali, setelah itu suhu lidah api mulai menurun namun masih mampu mendidihkan air sebanyak 3 kali lagi selama 105 menit dengan siklus yang mulai merenggang. Pada kompor 2, suhu di lidah api mencapai rata-rata sekitar $700{ }^{\circ} \mathrm{C}$ namun bertahan hanya sekitar 37,5 menit dan berhasil mendidihkan air sebanyak 4 kali. Setelah itu, suhu lidah api mulai menurun sampai sekitar $500{ }^{\circ} \mathrm{C}$ dan masih mampu mendidihkan air sebanyak 3 kali dan berlangsung selama 60 menit dengan siklus yang mulai merenggang.

Laju konsumsi bahan bakar kedua kompor ditampilkan dalam bentuk grafik seperti terlihat pada Gambar 5 sebagai berikut :

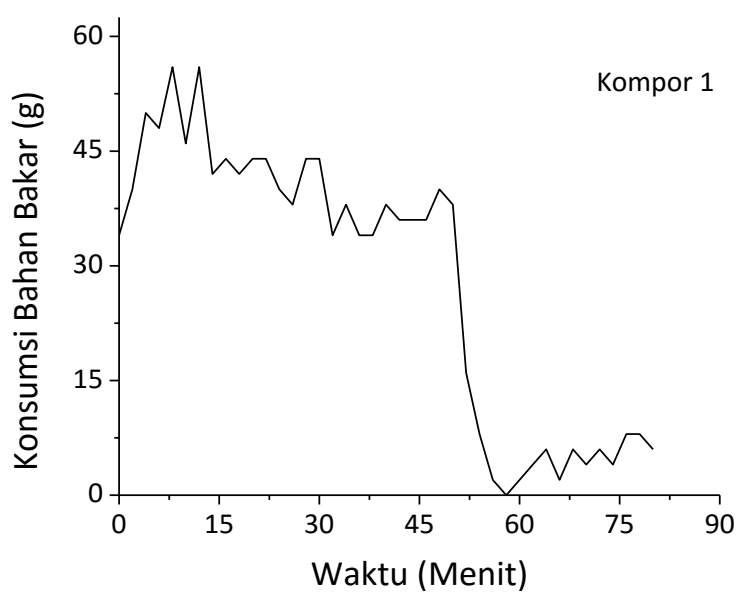

(a)

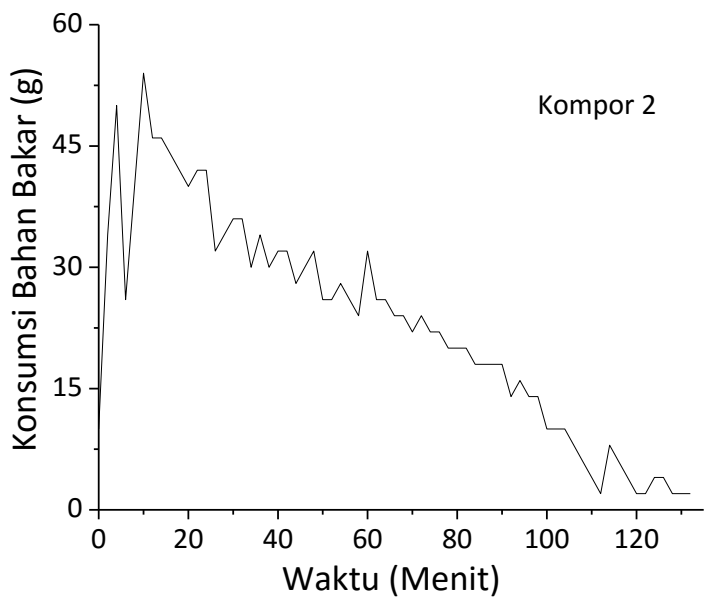

(b)

Gambar 5. Konsumsi bahan bakar pada a) kompor 1 dan b) kompor 2 
Dari Gambar 5a, laju konsumsi bahan bakar pada kompor 1 tertinggi terjadi pada 12 menit pertama dengan jumlah konsumsi bahan bakar sebanyak 330 gram atau ekuivalen dengan laju 27,5 g/menit. Sementara, untuk mencapai suhu rata-rata $600{ }^{\circ} \mathrm{C}$, laju konsumsi bahan bakar rata-rata sekitar $17 \mathrm{~g} / \mathrm{menit}$. Konsumsi bahan bakar mengalami penurunan pada rentang 14 - 48 menit (relatif stabil) dengan laju rata-rata 20 g/menit. Kemudian terjadi penurunan tajam laju konsumsi bahan bakar pada menit ke 50 sampai bahan bakar habis terbakar (menit ke 78). Jadi kompor 1 berperformansi secara efektif sekitar 50 menit.

Dari Gambar 5b, laju konsumsi bahan bakar pada kompor 2 tertinggi terjadi pada 10 menit pertama dengan jumlah konsumsi bahan bakar sebanyak 214 gram atau dengan laju konsumsi 21,4 g/menit. Namun setelah itu, terjadi penurunan laju konsumsi bahan bakar yang tajam sampai bahan bakar habis terbakar pada menit ke 132,

Efisiensi Pembakaran dihitung berdasarkan perbandingan konversi karbon yang ada dalam bahan bakar sehingga tersisa dalam abu pembakaran menggunakan rumus (2). Hasil analisa kandungan karbon dalam bahan bakar dan dalam abu sisa pembakaran disajikan dalam Tabel 1 sebagai berikut :

Tabel 1. Kandungan Karbon dalam Bahan Bakar dan dalam Abu Sisa Pembakaran

\begin{tabular}{ccc}
\hline Parameter & $\begin{array}{c}\text { Kompor } 1 \\
(\mathrm{~g})\end{array}$ & $\begin{array}{c}\text { Kompor } 2 \\
(\mathrm{~g})\end{array}$ \\
\hline C Awal & 95,17 & 95,17 \\
C Akhir & 0,48 & 1,75 \\
\hline
\end{tabular}

Efisiensi pembakaran kompor 1 adalah 99,5\% sedangkan kompor 2 sebesar 98,2 \%. Kedua kompor menunjukkan efisiensi pembakaran yang tidak jauh berbeda.

Emisi pembakaran menggambarkan emisi gas $\mathrm{CO}, \mathrm{NO}_{\mathrm{x}}$ dan $\mathrm{SO}_{\mathrm{x}}$ selama bahan bakar dibakar. Ketiga jenis gas tersebut sangat berbahaya bagi seseorang yang selalu berada di dekat kompor selama kegiatan memasak. Hasil uji emisi kompor 1 dan 2 ditunjukkan pada Gambar 6.

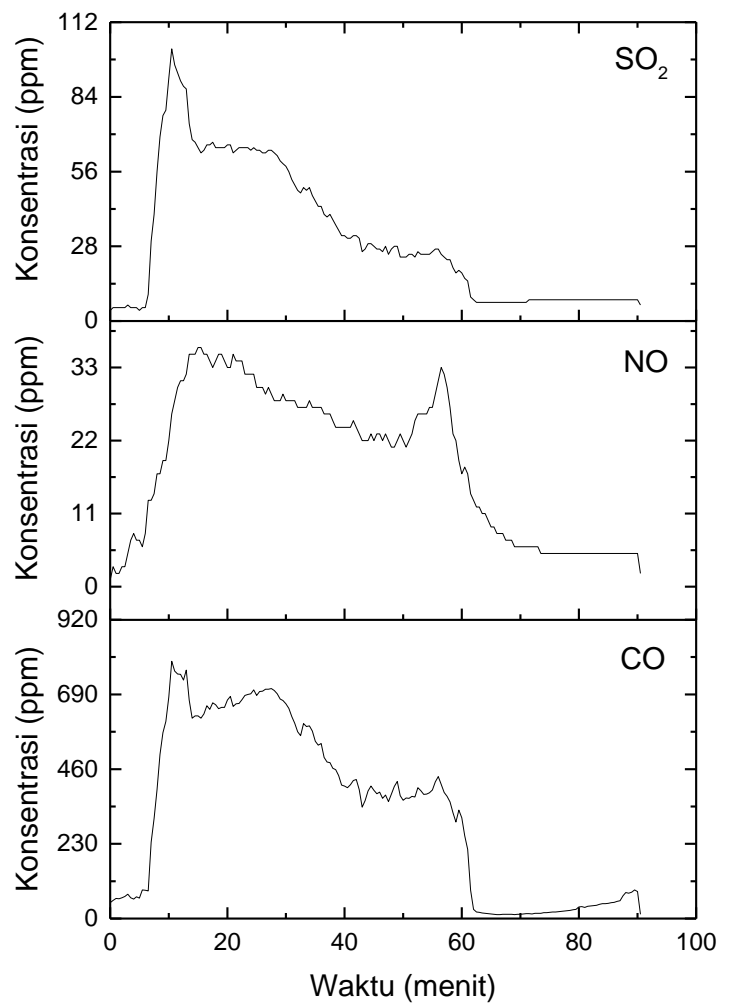

(a)

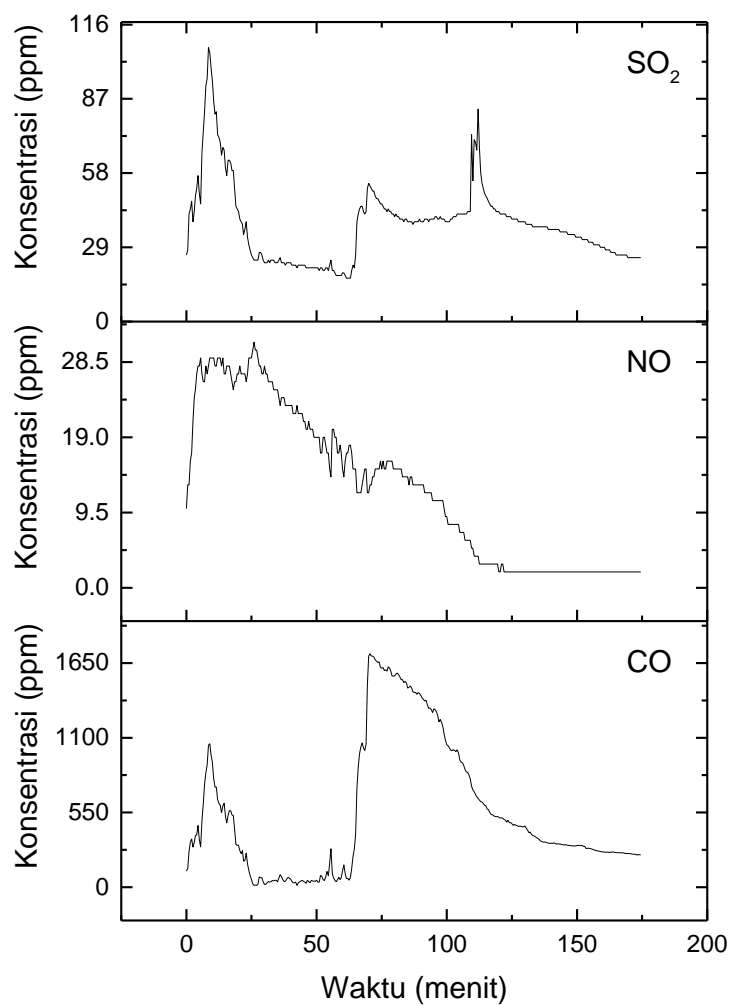

(b)

Gambar 6. Hubungan konsentrasi emisi gas buang terhadap waktu pada a) kompor 1 dan b) kompor 2

Pada kompor 1, emisi $\mathrm{SO}_{\mathrm{x}}$ yang dihasilkan selama pembakaran rata-rata $31 \mathrm{ppm}$ (minimal 4 ppm dan maksimal $102 \mathrm{ppm}$ ), sedangkan kompor 2 emisi $\mathrm{SO}_{\mathrm{x}}$ yang dihasilkan selama pembakaran rata-rata $38 \mathrm{ppm}$ (minimal 17 ppm dan maksimal 107 ppm). Sementara emisi $\mathrm{NO}_{\mathrm{x}}$ yang dihasilkan kompor 1 selama pembakaran 
rata-rata 19 ppm (minimal 1 ppm dan maksimal 36 ppm), sedangkan kompor 2 emisi $\mathrm{NO}_{\mathrm{x}}$ yang dihasilkan selama pembakaran rata-rata 13 ppm (minimal $2 \mathrm{ppm}$ dan maksimal $31 \mathrm{ppm}$ ). Selain itu, emisi CO yang dihasilkan oleh kompor 1 selama pembakaran rata-rata 328 ppm (minimal 12 ppm dan maksimal 792 ppm), sedangkan kompor 2 emisi CO yang dihasilkan selama pembakaran rata-rata 555 ppm (minimal 13 ppm dan maksimal 1719 ppm).

Dari Gambar 6 secara umum terlihat bahan konsentrasi tertinggi dihasilkan pada menit awal pembakaran, namun setelah itu berkecenderungan menurun.

\section{KESIMPULAN}

Desain kompor berbahan bakar biomasa untuk tungku bakar 1 dan 2 dianalisa berdasarkan dimensi untuk mendapatkan performa yang optimal. Performa kompor biomasa 1 lebih baik dibandingkan kompor 2 dengan nilai efisiensi pembakaran yaitu 99,5\% (kompor 1) dan 98,2\% (kompor 2). Sementara itu, efisiensi termal dari kompor 1 dan 2 adalah 25,4 dan 11,1\%. Emisi gas buang dari kompor 1 yaitu $\mathrm{CO}=328 \mathrm{ppm}, \mathrm{SO}_{\mathrm{x}}=31 \mathrm{ppm}$, dan $\mathrm{NO}_{\mathrm{x}}=$ 19 ppm. Sedangkan kompor 2 memiliki emisi gas buang $\mathrm{CO}=555 \mathrm{ppm}, \mathrm{SO}_{\mathrm{x}}=38 \mathrm{ppm}$, dan $\mathrm{NO}_{\mathrm{x}}=13 \mathrm{ppm}$. Dengan demikian, performa kompor 1 relatif lebih baik dibanding kompor 2.

\section{DAFTAR PUSTAKA}

[1]. Resiana Winata, Perancangan dan Optimasi Kompor Gas Biomasa yang Beremisi Gas CO rendah Menggunakan Bahan Bakar Pelet Biomasa dari Limbah Bagas, FT UI, 2012

[2]. The Apex Consulting Group, Kasus Kompor Biomassa Bersih di Indonesia, Sebuah Inisiatif Pemerintah Indonesia dan Bank Dunia, 2013

[3]. Dijan Supramono dan Resiana Winata, Unjuk Kerja Kompor Gas Biomassa dengan Bahan Bakar Pellet Biomassa dari Limbah Bagas Tebu, Seminar Nasional Teknik Kimia Indonesia dan Musyawarah Nasional APTEKINDO, 2012

[4]. Rahmad Hari Purnomo, Endo Argo Kuncoro, Dian Wahyuni, Rancang bangun dan uji teknik kompor berbahan bakar limbah biomasa pertanian, Buana Sains, Vol.14 No.2: 71-78, 2014.

[5]. Arga Setia Tama, Sarwono dan Ronny Dwi Noriyanti, Perancangan Kompor Briket Biomass untuk Limbah Kopi, Jurnal Teknik Pomits Vol 1 No 1, 2012.

[6]. SNI 7498 : 2008, Kompor Briket Batubara

[7]. Annual Book of Standards ASTM-D5373, 2014

[8]. --, Method 3 USEPA, Gas Analysis for Carbon Dioxide, Oxygen, Excess Air, and Dry Molecular Weight, California: Air Resources Board, 1999. 